\title{
Uncomfortable prescribing decisions: a critical incident study
}

\author{
Colin P Bradley
}

\begin{abstract}
Objective-To explore the discomfort experienced by general practitioners in relation to decisions about whether or not to prescribe.

Design-Focused interviews of general practitioners about prescribing decisions that made them uncomfortable. Analysis based on the critical
\end{abstract} incident technique.

Setting-One family practitioner committee area in the north of England.

Respondents-69 principals and five trainee general practitioners.

Main outcome measures-Drugs and clinical problems associated with prescribing discomfort. Reasons given by doctors for making the prescribing decisions they did and reasons for feeling uncomfortable.

Results-Antibiotics, tranquillisers, hypnotics, and symptomatic remedies were most often associated with discomfort, but any prescribable item could be associated with discomfort. Respiratory diseases, musculoskeletal problems, and anxiety were most often associated with discomfort, but again any condition could be associated. The main reasons given for the decisions made were patient expectation, clinical appropriateness, factors related to the doctor-patient relationship, and precedents. The main reasons given for feeling uncomfortable were concern about drug toxicity, failure to live up to the general practitioner's own expectations, concern about the appropriateness of treatment, and ignorance or uncertainty.

Conclusions-Many considerations, including medical, social, and logistic ones, influence the decision to prescribe in general practice. The final action taken depends on a complex interaction of these disparate influences.

\section{Introduction}

Any attempt to influence the prescribing behaviour of doctors ought to be based on a thorough understanding of how prescribing decisions are actually made. A key decision, made primarily by general practitioners, is whether or not to deal with the patient's problem by issuing a prescription. Many have speculated on how this decision is made, but there is little empirical evidence.' Howie has shown that the decision to prescribe antibiotics for sore throats is strongly influenced by social information about the patient. ${ }^{2}$ Harris too, in a small study of decisions deemed to be "pharmacologically dubious," found them to be motivated primarily by social objectives.

The decision making that leads to prescribing in general practice is difficult to study. Decisions are made rapidly and usually without much conscious effort on the part of the prescriber. Sometimes, however, the decision is not straightforward. Several preliminary studies have confirmed that general prac- titioners can identify occasions when decisions have left them feeling uncomfortable. ${ }^{4}$ I therefore undertook a detailed study of the phenomenon of uncomfortable prescribing to improve the understanding of decision making over whether to prescribe. The aim of the study was to determine $(a)$ whether the discomfort is related to particular drugs or to particular patient characteristics such as morbidity and $(b)$ the reasons the doctors made the decisions they did and why they felt uncomfortable.

\section{Subjects and methods}

THE CRITICAL INCIDENT TECHNIQUE

The method used was modelled on the critical incident technique described by Flanagan. ${ }^{56}$ The technique focuses on respondents' accounts of events that have actually happened (incidents) rather than on generalisations or opinions.

Incidents are deemed to be critical when the purpose of the action and the outcome of the incident are reasonably clear and relevant to the phenomenon under study. Incidents so selected are then scrutinised by a panel of experts, who categorise them on the basis of inductive judgments. Categories are sought until all the incidents can be assigned. Further incidents are collected and analysed until no further categories appear to emerge from the data. A key feature of this method is that the categories are derived purely from the data and not on the basis of preconceived theories.

\section{RECRUITMENT OF PARTICIPANTS}

All the doctors on the medical list of a single family practitioner committee list in the north of England were contacted and invited to participate in the study. Sixty nine of the 168 doctors on the list $(50.7 \%)$ were interviewed. Five trainee general practitioners were also recruited. The study was conducted over one year from March 1987.

Respondents were from a wide range of ages, backgrounds, and practice situations, though younger doctors, women doctors, doctors with higher qualifications, and doctors in practices with more partners and smaller list sizes per doctor were slightly overrepresented in the study group.

\section{CONDUCT OF THE INTERVIEW}

Ten working days before the interview doctors were contacted and asked to look out for occasions where a decision they had taken about whether or not to prescribe had made them feel uncomfortable. They were sent an encounter form to encourage them to record a few details about the patient to use as an aide memoire during the interview.

Doctors were interviewed about the incidents they recalled using a schedule which asked them about the drug or drugs concerned; the condition(s) or problem(s) of the patient; the action taken-that 
is, whether or not a prescription was issued; the reasons for the action; and the reasons for feeling uncomfortable.

\section{ANALYSIS OF THE INCIDENTS}

Interviews were taperecorded and transcribed. Following the recommendations of Flanagan, ${ }^{5}$ I assembled a panel of experts in general practitioner prescribing to help with the analysis. Members of the panel were sent batches of incidents extracted from the interviews. At a series of meetings the incidents were categorised. A schema for categorising incidents was devised based on the first 50 incidents to be analysed. An example of an incident and how it was analysed is given in the appendix.

The schema was amended and refined by examining further batches of incidents until a final version of the schema which encompassed all points raised by all the incidents was agreed. I then reviewed all the incidents once more to check on the assignment of incidents to categorise and to count the frequencies of various factors that occurred in incidents.

\section{Results}

The 74 doctors provided details of 307 incidents (mean (SD) $4 \cdot 1(2 \cdot 0)$ ). Three doctors did not provide accounts of incidents that were suitable for analysis.

Antibiotics, tranquillisers or hypnotics, and symptomatic remedies were the drugs whose prescription most often led to feelings of discomfort (table I). Only one drug or drug group was mentioned in 252 incidents; two in 42 incidents, and three in 13 incidents. Table I lists the drug categories of the principal drug involved in incidents with comparative data for the North Western region as a whole.

Respiratory tract infections were by far the commonest conditions in incidents when the doctors felt uncomfortable (table II). Only one medical problem was mentioned in 225 incidents; two in 66 incidents, and three in 16 incidents (table II). Table II also gives comparative data from the third national morbidity survey for the region as a whole.

Table III lists the reasons given by doctors for the decision they made. Patients' expectations were one factor in just under half the incidents. Table IV gives the reasons the doctors gave for feeling uncomfortable. These were more varied but the most common reason was concern about drug toxicity and the second most common failure to live up to the doctor's own expectations of himself or herself.

TABLE I-Drug groups of principal drugs mentioned in incidents of prescriber discomfort ranked in order of frequency of mention and compared with number of prescriptions as a percentage of the total for North Western region, $1987^{\circ}$

\begin{tabular}{|c|c|c|}
\hline Drug category & $\begin{array}{l}\text { No }(\%) \text { of } \\
\text { incidents } \\
\text { in which } \\
\text { mentioned }\end{array}$ & $\begin{array}{c}\% \text { Of all } \\
\text { prescriptions } \\
\text { North Western region } \\
1987\end{array}$ \\
\hline Antibiotics & $70(23)$ & $12 \cdot 2$ \\
\hline Tranquillisers and hypnotics & 57 (18) & $8 \cdot 2$ \\
\hline Symptomatic remedies & $31(10)$ & NA \\
\hline Cardiovascular drugs & $19 \quad 6)$ & $16 \cdot 7$ \\
\hline \multirow{2}{*}{\multicolumn{3}{|c|}{ Oral contraceptives and hormone }} \\
\hline & $15 \quad(5)$ & $4 \cdot 8$ \\
\hline Non-steroidal anti-inflammatories & $12(4)$ & $5 \cdot 2$ \\
\hline Drug unstated & $11 \quad(4)$ & NA \\
\hline Corticosteroids & $10 \quad(3)$ & No data \\
\hline Opiates and narcotics & $9 \quad(3)$ & No data \\
\hline Other analgesics & $8 \quad(3)$ & $6 \cdot 2$ \\
\hline Ulcer healing drugs & $8 \quad(3)$ & $2 \cdot 1$ \\
\hline Slimming tablets & $8 \quad(3)$ & $<0 \cdot 1$ \\
\hline Antidepressants & 7 (2) & 1.8 \\
\hline Vitamins and tonics & 7 (2) & $1 \cdot 7$ \\
\hline$\beta$ Agonists & $5 \quad(2)$ & 3.5 \\
\hline Other psychotropics & 4 (1) & No data \\
\hline Dressings and appliances & $2(<1)$ & $2 \cdot 4$ \\
\hline All other drugs & $24(8)$ & NA \\
\hline
\end{tabular}

$\mathrm{NA}=$ not available
TABLE II -Diseases or problems mentioned in incidents of prescriber discomfort ranked in order of mention and compared with incidence of conditions in third national morbidity survey

\begin{tabular}{lcc}
\hline & $\begin{array}{c}\text { No(\%) of } \\
\text { incidents } \\
\text { in which } \\
\text { mentioned }\end{array}$ & $\begin{array}{c}\text { \% Of } \\
\text { consultations } \\
\text { in third national } \\
\text { morbidity survey }\end{array}$ \\
Disease or problem & $92(23)$ & 16 \\
Respiratory tract diseases & & \\
$\begin{array}{l}\text { Urological and gynaecological problems } \\
\text { (including urinary tract infection) }\end{array}$ & $31(10)$ & $4 \cdot 9$ \\
Musculoskeletal problems & $29(7)$ & $8 \cdot 5$ \\
Anxiety & $29(7)$ & $1 \cdot 6$ \\
Other single medical problems & $29(7)$ & $\mathrm{NA}$ \\
Drug and alcohol misuse & $24(6)$ & $0 \cdot 2$ \\
Social problems & $22(5)$ & $\mathrm{NA}$ \\
Cardiovascular problems & $21(5)$ & $8 \cdot 9$ \\
Gastrointestinal problems & $18(4)$ & $3 \cdot 9$ \\
Depression & $18(4)$ & $2 \cdot 1$ \\
Metabolic and endocrine problems & $17(4)$ & $2 \cdot 2$ \\
$\quad$ including obesity) & $15(4)$ & $0 \cdot 4$ \\
Sleep disturbance & $15(4)$ & $\mathrm{NA}$ \\
Other psychiatric/psychological & $16(4)$ & $5 \cdot 9$ \\
$\quad$ problems & $11(3)$ & $7 \cdot 6$ \\
Skin diseases & $9(2)$ & $\mathrm{NA}$ \\
Neurological problems & $9(2)$ & $\mathrm{NA}$ \\
Complex or multiple problems & & \\
Problem unstated & & \\
\hline
\end{tabular}

TABLE III -Reasons given by study doctors for decisions made

\begin{tabular}{lc}
\hline Reason for decision & $\begin{array}{c}\text { No of } \\
\text { incidents }\end{array}$ \\
\hline Patient expectation & 138 \\
Clinical appropriateness & 90 \\
Factors relating to doctor-patient relationship & 71 \\
Factors relating to precedents & 67 \\
Lack of alternative treatment options & 36 \\
Risk of serious illness & 29 \\
Logistic problems including lack of time & 25 \\
To avoid drug toxicity & 25 \\
Need to do something & 21 \\
Cost of drug & 18 \\
To avoid extra work & 17 \\
To achieve other (non-treatment related) objectives & 15 \\
To avoid problems of drug withdrawal & 12 \\
As a therapeutic trial & 10 \\
\hline
\end{tabular}

TABLE IV-Reasons for discomfort experienced by study doctors

Reason for discomfort $\quad \begin{gathered}\text { No of } \\ \text { incidents }\end{gathered}$

Concerns about drug toxicity 83

Failure to live up to own expectations Concerns about appropriateness of treatment Ignorance/uncertainty about management Concerns about negative patient evaluation Concerns about negative patient evaluation
Ignorance/uncertainty about diagnosis Ignorance/uncertainty about diagnosis
Feeling of lack of contro//being manipulated Feeling of lack of control/being manipu
Failures of doctor-patient relationship Failures of doctor-patient relationship
Concerns about negative peer evaluation Concerns about
Anger/irritation Anger/irritation

Concerns about workload/time managemen Concerns about cost of treatment Concerns about setting/breaking precedents Past events of special importance

\section{Discussion}

This is a qualitative study of the decision to prescribe. Thus, the numbers of incidents in each category has a strictly limited value in indicating the relative importance of each factor in determining prescribing behaviour. Further studies of a different design would be required to determine their relative importance.

The main value of this study lies in its exposure of the complexity of the decision making that precedes prescribing in general practice. It also suggests that prescribing discomfort is a universal, or near universal, experience of prescribers. Furthermore, this discomfort can arise over almost any prescribable item and any clinical condition. The combination of factors influencing the decision makes for difficulty rather than the occurrence of any one factor.

Rational prescribing has been defined as prescribing that is appropriate, safe, effective, and economic. ${ }^{10} \mathrm{On}$ 
these criteria much prescribing in general practice is judged to be irrational. More fundamentally, however, rationality implies that reasoned thought has been applied in arriving at a decision. This study indicates that some prescribing decisions have required a great deal of thought. Far from acting irrationally, the prescriber is struggling to balance several disparate considerations and work out what to do for the best. There is a rationale; it is just not purely pharmacological.

A major thrust of governmental and professional efforts to reduce "irrational prescribing" is directed at educating prescribers. Ignorance is indeed a problem, as is highlighted in this study. Nevertheless, there are clearly many instances where the prescriber is awareindeed uncomfortably aware - of the problems about appropriateness, safety, efficacy, and cost but these considerations are outweighed by others such as the demand of the patient or simply lack of sufficient time to negotiate a different management. Education which fails to tackle these other issues around the prescribing decision may fail to change prescribing behaviour and serve only to increase the level of prescriber discomfort.

In particular, doctors need education in how to avoid prescribing when it is not clinically indicated. This will require the doctor to develop skills in negotiating about whether or not the patient's expectation for a prescription should be fulfilled. Changes of treatment, which involve breaking precedents, may also need to be negotiated. Being able to offer alternative treatments would be a help in the negotiation, and there is evidence that doctors are not well trained in offering non-drug alternatives. " Dealing with the risk of serious illness needs education about what the real risks are and knowledge of how risks are perceived. ${ }^{12}$ Similarly, there are specific skills required to deal with that irreducible uncertainty which is intrinsic to medical practice. Managing all this within the time constraints of an ordinary general practice consultation requires extraordinary time management skills and considerable skill in communication to maintain a good doctor-patient relationship. Based on the scenarios described by the doctors in this study, I have devised an educational exercise called "learning to say no." It seeks to address, through an experiential learning technique, many of these issues.

Finally, it could be argued that the discomfort itself should be dealt with in an educational setting. Certainly, it would help if experiences of medical misadventure were dealt with in a peer group setting and put into their proper perspective. But prescribing discomfort is not a wholly negative experience and it should not be eliminated altogether. Having some discomfort about decisions indicates that the prescriber is continually thinking about his or her prescribing. To experience no discomfort would be dangerous, and doctors should value prescribing discomfort for what it can teach them about their own prescribing behaviour. A study of one's own prescribing discomforts might be more educational than the assimilation of yet more information about the actions, side effects, and costs of drugs.

I thank all the doctors who participated for giving their time and being so frank. I thank Professor Conrad Harris, Professor Philip Reilly, and Dr David Wilkin for serving as the expert panel. This study was funded by a grant from the scientific foundation board of the Royal College of General Practitioners.

1 Bradley CP. Prescribing patterns and decision making - a literature review. Fam Pract 1991;8:276-87.

2 Howie JGR. Clinical judgment and antibiotic use in general practice. $B M \mathcal{F}$ 1976;ii:1061-4.

3 Harris CM. Personal view. BMF 1980;281:57.

4 Bradley CP. A critical incident study of general practitioners' discomfort arising from prescribing decisions. [MD Thesis.] University of Dublin, Trinity College, 1990.

5 Flanagan JC. The critical incident technique. Psych Bull 1954;51:327-58.

6 Bradley CP. Turning anecdotes into data-the critical incident technique. Fam Pract (in press)

7 Glaser BG, Strauss AL. The discovery of grounded theory: strategies for qualitative research. New York: Aldine Publishing Company, 1967.

8 Department of Health and Social Services. Health and personal social services statistics. London: HMSO, 1989.
s.

9 Royal College of General Practitioners, Office of Population Censuses and Surveys, Department of Health and Social Security. 1981-1982 Morbidity statistics from general practice: third national study. London: HMSO, 1986.

10 Parish PA. Drug prescribing - the concern of all. $R$ Soc Health $f$ 1973;93: 213-7.

11 Hemminki E. The role of prescriptions in therapy. Med Care 1975;13:150-9.

12 The British Medical Association. The BMA guide to living with risk. London: Wiley, 1987.

(Accepted 30 October 199I)

\section{Appendix-Analysis of a typical incident}

The following is a verbatim quotation extracted from the interview with one respondent.

"There is a middle aged, about 40ish, 45, [woman] who...she is a nurse. Looking through the notes... periodically gets sleeping tablets for no terribly good indication, because she's having difficulties at work or whatever. It was an instance like, 'Dr $M$ always gave those to me.' I just ran into a brick wall when I asked her what particular stress or particular strain she had. We get a very high level of expectation . . . in the negotiations I felt as if I had the underhand and was being dictated to. I was squirming. I suppose it is this feeling of loss of control ... as though I am not in charge. My [previous] practice nurse remarked that she didn't think I was very good with nurses, in particular, because I tended to become too defensive. When I got defensive I used to go perhaps overboard in not playing the sort of paternalistic doctor and too concerned to get their view of things and to get their view of how they should be treated. Perhaps too nervous. I suppose it goes back to being a houseman and being under sister's thumb."

Analysis-In this incident the prescription is for an unspecified sleeping tablet prescribed for no clear indication. The reasons for action included the fact that the patient had had them before from a previous doctor (precedent) and was expecting them (patient expectation). The discomfort relates to the doctor's feeling of being dictated to by the patient and a feeling of not being in control of either the patient or the situation (lack of control). The doctor is also describing a general discomfort engendered in him by patients who are nurses (global discomfort). There is also a contribution to the doctor's discomfort from his apparent inability to adhere to his own principles of how things ought to be done (failure to live up to his own expectations of himself). 